\title{
Phenylketonuria in Sohag: A Preliminary Study
}

\section{Amira Mourad ${ }^{1}$, Tahia H. Saleem ${ }^{2}$, Nagwa S. Ahmed ${ }^{3}$ and Sawsan M.A.} Abuhamdah ${ }^{4, *}$

${ }^{1}$ Department of Medical Biochemistry, Faculty of Medicine, Sohag University P $P^{2}$ Department of Medical Biochemistry, Faculty of Medicine, Assiut University, ${ }^{3}$ Department of Medical Biochemistry, Faculty of Medicine, Sohag University, Egypt, ${ }^{4}$ Department of $P$

Biopharmaceutics and Clinical Pharmacy, Faculty of Pharmacy, University of Jordan.

\begin{abstract}
Phenylketonuria (PKU) is one of the commonest inborn error of metabolism, it is an autosomal recessive metabolic genetic disorder characterized by a mutation in the gene for the hepatic enzyme phenylalanine hydroxylase (PAH), rendering it nonfunctional. The diagnosis of this disorder can be confirmed by analysis of urine components. The present study aimed to assess the prevalence of PKU among children aged 6 months to 6 years in Sohag governorate Egypt, its relationship to malnutrition and identifying families with higher predisposition to having children with inborn errors of metabolism. One hundred children were selected from 18,000 patients seen in the pediatric neuropsychiatry clinic of Sohag University hospital over three years, between May 2008 - May 2011. They were presented with clinical symptoms suggestive of probable preliminary diagnosis of PKU. Proper clinical and laboratory investigations, including ferric chloride test in urine, total protein and albumin in serum, were screened to confirm the diagnosis. PKU was diagnosed in two children cases. The diagnosed cases were suffering from mild malnutrition represented by low levels of serum albumin and total protein comparable to cases of Marasmus and kwashiorkor or other deficiencies like rickets. Screening of the newborn with special emphasis on PKU is highly recommended before discharge from the nursery for children delivered in the hospital or on first visit to the clinic for children delivered at home. Early detection would help prevent serious and permanent neurological impairment.
\end{abstract}

Keywords: Phenylketonuria (PKU), Inborn Errors of Metabolism (IEMs), Sohag Governorate, Egypt, Phenylalanine Hydroxylase, Neurological Impairment, Newborn Screening.

\section{Introduction}

Many inborn errors of metabolism (IEMs) are classified as organic acidemia, in which organic acids accumulate in the urine (Kuhara, 2007). Human urine contains numerous metabolic intermediates at a variety of concentrations that can provide clues for diagnosing inborn errors of metabolism and other genetic mutations (Albers et al., 2001; Blau et al., 1996; Imamura et

al., 1999; Lee et al., 2011).
For most of the cases with IEMs, the clinical presentations are variable and nonspecific and routine laboratory tests do not usually identify the etiology of the disease. Metabolite analysis can comprehensively detect enzyme dysfunction caused by a variety of abnormalities (Kuhara, 2007; Ponzone et al., 1990).

Phenylketonuria (PKU) is an autosomal recessive genetic disorder characterized by a deficiency in the Enzyme phenylalanine hydroxylase. 
When this enzyme is deficient, phenylalanine accumulates and is converted to phenyl pyruvate, which is also known as phenylketone, which is detectable in the urine. Other unknown factors also interfere in determining the metabolic profile of PKU (Oh et al., 2004; Blau et al., 1996). It is important to emphasize that early diagnosis and treatment are critical for patients with IEMs. The present study aims to identify the prevalence of PKU among children aged 6 months to 6 years seen in the pediatric clinic of Sohag University. Relationship of this disease to malnutrition was also investigated through determining the total protein and albumin in the sera of the children. Families predisposed to have children with this IEMs are also identified and counseled. It is important to test the validity and the practicality of using inexpensive biochemical laboratory tests beside the clinical neurophysiologic criteria for diagnosing PKU in an underprivileged locality

\section{Patients and Clinical Examination}

The study was approved by the clinical ethics committee of the Sohag Faculty of Medicine. One hundred children, aged 6 months to 6 years, were selected from 18,000 patients examined in the pediatric clinics of Sohag University hospital over 3 years from May 2008 to May 2011. They presented with clinical symptoms suggestive of probable preliminary diagnosis of PKU. Depending on the severity of symptoms they were seen either as outpatients or were admitted as inpatients. These symptoms included delayed milestones of growth, vomiting since birth, blonde hair and eyebrows, jaundice and organomegaly, rickets, diarrhea, pneumonia, convulsions and skeletal deformities. Exclusion criteria from the study included cerebral palsy, myasthenia gravis, primary muscular dystrophies, myotonia congenita, polymyositis, mental retardation, epilepsy, Friedrich's ataxia, hereditary spastic paraplesia, poliomyelitis and cardiostenosis.

For all children participating in the study, informed written consent was obtained from a parent or next of kin. Children and parents were interviewed for full social and clinical history taking, including consanguinity between parents, history of sibling death, congenital anomalies and IEMs , especially PKU. Physical examination of the children covered the general look, hair changes, developmental milestones, head circumference and congenital anomalies. Full neurological examination was carried out for general behavior, muscle power and reflexes. Chest and abdominal examination was done for detection of organomegaly.

\subsection{Biochemical methods}

A sample of $5 \mathrm{ml}$ blood was withdrawn from each child and allowed to clot at room temperature. The samples were centrifuged at 3,000 rpm and the sera were separated and stored frozen at $-20{ }^{\circ} \mathrm{C}$ until used for assaying the chosen parameters using commercial kits. Serum total protein was determined by the Biuret method (Henry, 1964) and serum albumin by a modified bromocresol green binding assay (Tietz, 1995). Urine samples were also obtained and screened for PKU using the ferric chloride method (Berry et al., 1958). 


\section{Results}

Females were predominant in the studied cohort (65\%). The ages of $49 \%$ of the studied children were two years or less, while $39 \%$ were between 2 and 4 years. The remaining $12 \%$ aged between 4 and 6 years. The common presentations among the studied children are presented in Table 1. It could be seen that gastrointestinal manifestations constituted most of the complaints. Deficiency manifestations like delayed growth milestones and rickets also ranked high. By reviewing family history, it was found that sibling deaths were reported in $13 \%$ of cases and mental retardation in $5 \%$. Nine percent of the families reported consanguinity between parents. Physical examination of the children revealed congenital anomalies in 5 cases, in the form of polydactyle, cleft lip, cleft palate and ventricular septal defect. Three of these cases had consanguinity between parents.

\begin{tabular}{|ccccc|}
\hline Age & Frequency & Percent & $\begin{array}{c}\text { Valid } \\
\text { Percent }\end{array}$ & $\begin{array}{c}\text { Cumulative } \\
\text { Percent }\end{array}$ \\
\hline $\begin{array}{c}\text { Less than or } \\
\text { Equal 2 } \\
\text { years }\end{array}$ & 49 & 49.0 & 49.0 & 49.0 \\
\hline $\begin{array}{c}\text { Between 2 } \\
\text { and 4 } \\
\text { Years }\end{array}$ & 39 & 39.0 & 39.0 & 88.0 \\
\hline $\begin{array}{c}\text { More than 4 } \\
\text { Years }\end{array}$ & 12 & 12.0 & 12.0 & 100.0 \\
\hline Total & 100 & 100.0 & 100.0 & \\
\hline
\end{tabular}

Table 1. Age distribution of infants screened

During the course of the study, two cases of PKU were identified, based on laboratory tests, clinical presentation and family history. Both phenylketonuric infants were born in rural areas. Analysis of their family histories revealed that both infants were siblings of consanguineous parents. One of the infants had a family history of sibling deaths and the other had a family history of mental retardation.

Clinical examination of the two positive cases revealed typical presentation of PKU. Both infants suffered mild malnutrition expressed as decreased levels of serum total proteins and albumin comparable to cases of malnutrition of marasmus, kwashiorkor or other deficiencies like rickets (Table 2 ).

\begin{tabular}{|ll|}
\hline Complaint & Frequency \\
\hline Diarrhea & $19 \%$ \\
\hline Pneumonia & $15 \%$ \\
\hline Delayed growth milestones & $13 \%$ \\
\hline Rickets & $12 \%$ \\
\hline Vomiting & $11 \%$ \\
\hline Convulsions & $6 \%$ \\
\hline Jaundice and organomegaly & $5 \%$ \\
\hline $\begin{array}{l}\text { Coarse facial features } \\
\text { and skeletal deformities }\end{array}$ & $2 \%$ \\
\hline
\end{tabular}

1. Table 2. Common clinical presentations of the studied children 


\section{Clinical findings}

The first diagnosed case was a three year old girl of a consanguineous couple. The child presented with history of delayed growth milestones, repeated vomiting and hyperirritability since birth. She was treated for hypoxic ischemic encephalopathy with seizures. There was family history of mental retardation, but no sibling deaths, convulsions or albinism. The child had frequent myoclonic jerks with drooling of saliva. There was gross microcephaly with head circumference of $37 \mathrm{~cm}$. Overall motor, language and social developmental delays were noted. Brain CT scan was uneventful. Urine was tested for PKU by the ferric chloride method, and gave a positive result.

The second diagnosed case was a three and half years old boy of a sanguineous couple. Family history revealed death of 2 siblings after 1-2 weeks of birth. Clinical examination revealed delayed developmental parameters like walking, speaking and head support (Table 3). CNS examination showed normal higher mental functions. There was generalized hypotonia with normal plantar reflex and lordosis of the lumbar spine. The urine sample which was taken was turbid and foul smelling. Screening for PKU by the ferric chloride method was positive.

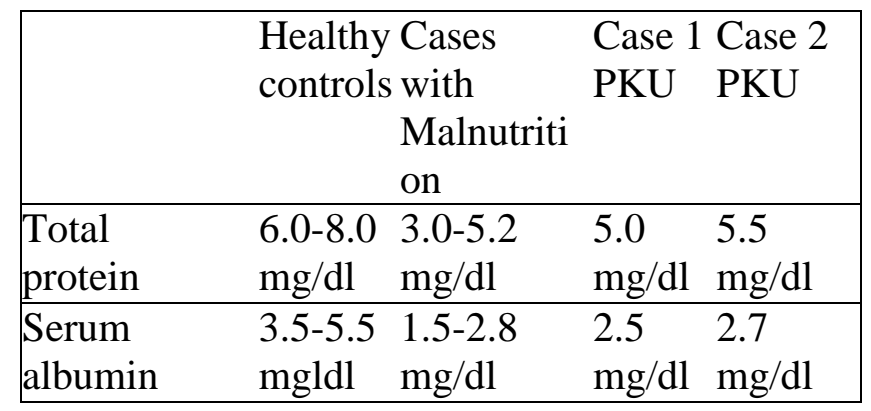

Table 3. Serum levels of total proteins and albumin in the diagnosed cases of PKU as compared to ranges of cases presented with malnutrition and healthy controls in the studied cohort.

\section{Discussion}

The use of the ferric chloride method for detecting phenyl pyruvate in urine as a screening procedure for PKU has been proven acceptable, easy and cheap. It is suitable for screening the newborn in underprivileged areas without large medical facilities. Out of the 18,000 cases seen in the pediatric clinics of Sohag University hospital over three years, one hundred were suspected and 2 cases were confirmed to have PKU. This prevalence of 1 in 9000 is higher than what was reported by other groups. However, increases in the number of diagnosed cases over time have been reported (Bhatt et al., 2008; Choudhuri et al., 2006; Kumta, 2005; Imamura et al.,
1999; Schulpis et al., 1991; Wuu et $a l .$, 1988). This may be attributed to advances in diagnostic technology, better coverage and reporting, and increased awareness.

Hypoproteinemia has been reported by Hanley and his co-workers (1970) in 5 of 32 infants treated with a special low phenylalanine formula. Generally, a phenylalanine- restricted diet consists of protein hydrolysate, amino acid mixtures, fruits and vegetables with minimal amount of natural animal products, usually milk, to meet the daily requirement of phenylalanine needed for early growth. In children with PKU, diet therapy could influence the immune system, not only by antigenic change, but also by 
producing changes in plasma lipids. It has been known to cause a marked reduction of arachidonic acid levels in both plasma total lipids and phospholipids of children with PKU during dietary intervention.

An added finding in the present study is the effect of consanguinity on the incidence of metabolic disorders, as we reported a higher incidence of parental consanguinity than other population studies. Because inborn errors of metabolism are extremely rare and random variation in their incidence is high, the diagnosis of even one extra case over a short time period may have an important effect on the birth prevalence of certain disorders.

In conclusion, we strongly recommend the expanded newborn screening for PKU for every baby born before discharge from the nursery for children delivered in the hospital or on first visit to the clinic for children delivered at home. Early diagnosis is important for treatment and genetic counseling. The ferric chloride method used in the present study for detection of PKU is simple, acceptable, inexpensive and can be used for screening in remote or underserved areas in the countryside.

\section{Reference}

1. Albers S, Marsden D, Quackenbush E, Stark AR, Levyand HL and Irons M. 2001. Detection of neonatal carnitine palmitoyltransferase II deficiency by expanded newborn screening with tandem mass spectrometry. Pediatrics, 107:1417.

2. Berry H K; Sutherland B, Guest G $\mathrm{M}$ and Warkany J. 1958. Simple method for detection of phenylketonuria. Journal of the American Medical Association, 167:18, 2189-2190.

3. Bhatt $\mathrm{C}$ Misraand $\mathrm{Z}$ and Goyel $\mathrm{N}$.
2008. Detection of inherited metabolic diseases in children with mental handicap. Indian $J$ Clinical Biochem., 23:1 10-16.

4. Blau N, Barnesand I and Dhondt JL.1996. International database of tetrahydrobiopterin deficiencies. $J$ Inherited Metabolic Dis., 19:1 814.

5. Choudhuri $\mathrm{T}$ and Sengupta $\mathrm{S}$. 2006. Inborn error of metabolism An Indian perspective. Int $J$ Human Genet, 6(1): 89-91.

6. Hanley W B, Linsao L, Davidson $\mathrm{W}$ and Moes CAF.1970. Malnutrition with early treatment of phenylketonuria. Pediatric Research, 4(4): 318-327.

7. Henry R J.1964. Clinical Chemistry: Principles and Techniques. New York, Harper and Row. p 183.

8. Imamura T, Okano Y, Shintaku H, Haseand $Y$ and Isshiki $G$

9. .1999. Molecular characterization of 6-pyruvoyl-tetrahydropterin synthase deficiency in Japanese patients. J Human Genetics, 44(3): 163-168.

10. Kuhara T. 2007. Non-invasive human metabolome analysis for differential diagnosis of inborn errors of metabolism. $J$ Chromatogr B Analyt Technol Biomed Life Sci. 855(1):42-50.

11. Kumta N B.2005. Inborn errors of metabolism (IEM) : An Indian perspective. Indian $J$ Pediatrics, 72:4 325-332.

12. Lee HH, Mak CM, Lam CW, Yuen YP, Chan AO and Shek CC. 2011. Analysis of inborn errors of metabolism: disease spectrum for expanded newborn screening in Hong Kong. Chin Med J; 124: 983-989.

13. Oh H J, Park ES, Kang S, Jo I and Jung SC .2004. Long-term enzymatic and phenotypic correction in the phenylketonuria 
mouse model by adeno-associated virus vector-mediated gene transfer. Pediatric Research, 56 (2): 278-284.

14. Ponzone A, Blau N, Guardamagna O, Ferrero GB, Dianzaniand I and Endres W.1990. Progression of 6-pyruvoyl- tetrahydropterin synthase deficiency from a peripheral into a central phenotype. J Inherited Metabolic Dis., 13(3): 298-300.

15. Schulpis K H, Covanis A, Loumakou M, Frantzis N, Papandreou O, Divolli A, Missiou-Tsagaraki S, Kierat L and Blau N.1991. A case of 6- pyruvoyl-tetrahydropterin

synthase deficiency after screening 1,500,000 newborns in Greece. $J$ Inherited Metabolic Dis., 14(5): 845-846.

16. Tietz NW. 1995. Clinical Guide to Laboratory Tests. $3^{\text {rd }}$ ed. Philadelphia, W.B. Saunders Co.

17. Wuu K D, Hsiao KJ, Chen $\mathrm{CH}$, Hsiao TS, Chang $\mathrm{YC}$ and Chu YK.1988. Screening for inherited metabolic diseases and congenital hypothyroidism in 4,744 mentally retarded school children in Taiwan. Jinrui Idengaku Zasshi. Japanese J Human Genetics, 33(1): 33-40. 